\title{
Marxismo e cultura: contraponto às perspectivas pós-modernas
}

David Romão Teixeira

Mestre em Educação pela UFSC e professor da UFRB

Fernanda Braga Magalhães Dias

Mestranda em Educação pela UFSC e professora da REE/Bahia

\section{Resumo}

Este artigo tem por objetivo apresentar a contribuição do marxismo ao debate sobre a cultura, destacando suas principais orientações e contrapontos ao debate pós-moderno. Expõe um panorama sintético do debate sobre cultura na atualidade, realiza um balanço da análise marxista sobre cultura, destacando as contribuições de Trotski sobre a temática e sua íntima ligação com o contexto revolucionário soviético e europeu de seu tempo. Ressalta a importância de compreender a interdependência dialética entre a cultura e a economia. Concluindo que a análise da cultura no campo do marxismo nos possibilita elencar orientações que demarcam a compreensão da cultura no campo da revolução social.

Palavras- Chaves: Cultura; Revolução; Marxismo.

\begin{abstract}
This article aims to present the contribution of Marxism to the debate about culture, highlighting its main lines and counterpoints to the postmodern debate. Outlines of overviews of the debate on culture today, carries a balance of the Marxist analysis of culture, highlighting the contributions of Trotsky on the subject and its intimate connection with the revolutionary Soviet and European context of his time. Emphasizes the importance of understanding the dialectical interdependence between culture and economy. Concluding that the analysis of culture in the field of Marxism enables us to list guidelines that demarcate the understanding of culture in the field of social revolution.
\end{abstract}

Keywords: Culture; Revolution; Marxism. 


\section{Introdução}

$\mathrm{E}$ ste artigo é resultado das reflexões realizadas no estudo de mestrado: "A necessidade histórica da cultura corporal em áreas de reforma agrária: caso do MST/Bahia". Tem como objetivo apresentar a discussão sobre cultura, reafirmando a contribuição materialista dialética neste debate, e destaca a hegemonia teórica atual das perspectivas irracionalistas e a-históricas, que desatrelam a cultura das relações de produção da existência, desenvolvendo assim, um anti-conceito que dificulta a compreensão da realidade concreta e a prática pedagógica dos que dispõem superar a ordem do capital.

No primeiro momento apresentaremos um panorama sintético do debate sobre cultura na atualidade; em seguida apresentaremos a contribuição marxista como contraponto à perspectiva hegemônica, destacando as contribuições de Trotski e sua íntima ligação com o contexto revolucionário soviético e europeu de seu tempo; e por fim, apresentaremos sinteticamente as contribuições marxistas ao debate da cultura e a importância da sua relação com o processo revolucionário.

\section{O debate contemporâneo sobre cultura}

Pensar a cultura desatrelada de um projeto histórico emancipador tem sido a regra, sob hegemonia ideológica do capital, preocupando-se cada vez mais com as diferenças existentes entre os seres humanos do que com as suas semelhanças. Desenvolve-se assim, uma perspectiva teórica que privilegia o micro em detrimento dos nexos e relações entre o singular e o universal e, em grande medida, por meio de um sistema de retroalimentação, os estudos sobre cultura tanto utilizam de tal perspectiva teórica para suas análises, como também servem para justificar a fundamentação da mesma. Nesse sentido, formula-se um ideário que tende para "o informe e o atípico, para o desgarrado e o eventual, para o mutante e o volátil" que nega sua condição de ideário "moderno e, daí, à falta de

\footnotetext{
${ }^{1}$ Desenvolvido no Mestrado em Educação no PPGE/UFSC, com o apoio da FAPESB.
} 
melhor termo ou de imaginação conceitual, [autodenomina-se] pósmoderno" (Bosi, 1992, p. 353). Ainda, segundo Alfredo Bosi:

A recusa ideológica de olhar para o todo natural-humano [...], pode dar-se ares de modéstia epistemológica (oxalá fosse); mas, a longo prazo, quem a sustenta como programa de pensamento e ação irá perdendo todo critério de valor, e se verá cúmplice das forças de desintegração e da morte. Diz o povo que o peixe fora d'água começa apodrecer pela cabeça (Bosi, 1992, p. 357, grifos nossos).

Em tempos onde a imprecisão conceitual torna-se lugar comum, inclusive em trabalhos acadêmicos, principalmente nas ciências humanas, limita-se a compreensão da realidade na sua concretude. Contemporaneamente a prática da ressignificação de conceitos adquire status de avanço na ciência (Moraes, 2003). Entre os conceitos que frequentemente são submetidos a ressignificações e alterações encontra-se o conceito de cultura, o que cria dificuldades para realização dos objetivos deste estudo, nos forçando a adentrar na investigação no campo controverso em que esse conceito se desenvolve. Muniz Sodré no desafio de apontar o significado do conceito de cultura apresenta o emaranhado teórico por trás dessa discussão.

Os antropólogos Kroeber e Kluckhohn puderam catalogar pouco mais de 150 definições, que só fazem atestar a natureza, ao mesmo tempo, movediça e tática, do conceito. Cultura é uma dessas palavras metafóricas (como por exemplo, liberdade) que deslizam de um contexto para outro, com significações diversas. É justamente esse "passe livre" conceitual que universaliza discursivamente o termo, fazendo de sua significação social a classe de todos os significados. A partir dessa operação, cultura passa a demarcar fronteiras, estabelecer categorias do pensamento, justificar as mais diversas ações e atitudes, a instaurar doutrinariamente o racismo e a se substancializar, ocultando a arbitrariedade histórica de sua invenção. É preciso não esquecer, assim, que os instáveis significados de cultura atuam concretamente como instrumentos das modernas relações de poder imbricadas na ordem tecno-econômica e nos regimes políticos, e de tal maneira que o domínio dito "cultural" pode ser hoje sociologicamente avaliado como o mais dinâmico da civilização ocidental (Sodré, 1983, p.8).

O conceito de cultura, na modernidade, é objeto de grandes discussões, principalmente na área das ciências humanas e, mais especificamente, na Antropologia. Devido à predominância teórica que não se encontra no campo marxista, vem se promovendo um longo e exaustivo 
debate sobre a questão cultural desatrelada, na maioria das vezes, da base material e com forte apelo as perspectivas idealistas e a-históricas.

$\mathrm{Na}$ história recente da humanidade o termo cultura tem sido empregado de diversas maneiras, como sinônimo e/ou antônimo do conceito de civilização; como noção limitada precisando de acréscimo para sua compreensão (ex.: "cultura das artes", "cultura pedagógica", "cultura das ciências" e etc.); como distintivo de classe (ex.: cultura erudita X cultura popular); como algo que pode ser interpretado, porém, não pode ser explicado ${ }^{2}$.

Após a Segunda Guerra Mundial, surgiu a noção de "áreas culturais" de Franz Boas, visão teórica que estabelece um abismo entre os ocidentais e as "raças inferiores", destinada, entre outras finalidades, a enfrentar o materialismo histórico. Nesse mesmo período, a antropologia passa por crises nos próprios fundamentos e, em resposta, o estruturalismo e, em seguida, o pós-modernismo com sua ênfase "multiculturalista" elogiando a descolonização, parecem ilusoriamente inverter a postura política num sentido progressista (Llobera apud Cardoso, 2007).

Cardoso (2007) aponta como exemplo, o pós-modernismo "perspectivista" que com freqüência oculta as lutas sociais e a ação imperialista tanto quanto faziam as correntes do pensamento dominantes em fases precedentes. A vitória nesse período do pós-modernismo, da concepção amputada de cultura, foi decisiva na transformação dessa noção num anti-conceito.

\section{Marxismo e cultura: algumas análises}

Partindo do referencial marxiano, nosso debate sobre cultura não se deterá em compreender a polissemia deste termo ${ }^{3}$, se preocupará mais com

\footnotetext{
2 [...] Gertz, como os pós-estruturalistas, deixou de considerar o método antropológico como científico: a cultura podia ser interpretada mas, não explicada (Cardoso, 2007, p. 07).

${ }^{3}$ Ainda que consideremos essa uma discussão importante, diante do desafio que está posto, a transformação da realidade, ela é insuficiente. É preciso centralizar os esforços na compreensão de como é produzida e reproduzida a cultura, até por que "[...] não é lutando contra a fraseologia de um mundo, que se luta com o mundo que realmente existe [...]" (Marx; Engels, 1980, p.17).
} 
sua interdependência com as outras esferas da produção da vida, sua forma de apropriação e seus limites emancipatórios sob a égide da sociedade do capital, destacando a participação da cultura como elemento constitutivo da ideologia, como também formador da consciência revolucionária.

$\mathrm{Na}$ produção marxista podemos encontrar o entendimento de cultura basicamente em duas perspectivas: uma ampla e outra mais restrita. $\mathrm{Na}$ perspectiva ampla, a cultura pode ser compreendida como uma criação do homem, resultante da complexidade crescente das operações de que esse animal se mostra capaz no trato com a natureza, e da luta a que se vê obrigado para manter-se em vida, independente de qualquer forma social. É, pois, a cultura o processo pelo qual o homem acumula as experiências que vai sendo capaz de realizar, discerne entre elas, fixa as de efeito favorável (Vieira Pinto, 1979) ${ }^{4}$.

Seguindo a definição de Lukács, a cultura aparece numa perspectiva mais restrita,

O conceito de cultura (em oposição à civilização) compreende o conjunto das atividades e dos produtos dotados de valor que são supérfluos em relação ao sustento imediato. Por exemplo, a beleza interna de uma casa pertence ao conceito de cultura; não sua solidez, nem sua calefação, etc. Se então nos perguntarmos: em que consiste a possibilidade social da cultura? Devemos responder que ela é oferecida pela sociedade na qual as necessidades primárias foram satisfeitas de tal maneira que não se requer um trabalho tão pesado que esgote por completo as forças vitais, isto é, onde existem energias disponíveis para a cultura (Lukács, 2007).

Compreendendo as relações entre a produção material e espiritual, bem como suas contradições, Trotski irá apresentar uma formulação que no nosso entendimento unifica as definições anteriores, demonstrando como elas devem se complementar, no sentido não de restringir, mas sim como um conjunto de elementos que compõe um todo abrangente. Nesse sentido, o autor afirma que:

\footnotetext{
${ }^{4}$ É importante notar que Vieira pinto vem de uma formação filosófica fortemente ligada ao existencialismo. O livro em questão, Ciência e Existência, faz parte do "terceiro quadrante" de sua produção teórica, conforme Freitas (2005). É no quarto quadrante que o autor faz a ruptura completa com essa tendência e se aproxima mais profundamente do marxismo. Mas, suas produções anteriores servem sobremaneira para nossas análises sobre a cultura uma vez que a preocupação com o trabalho é presente em todas as suas obras (Freitas, 2005, p.16).
} 
Cultura é tudo aquilo que foi criado, construído, apreendido, conquistado pelo homem no curso de toda a sua História, em contraposição ao que a natureza lhe deu, compreendida aí a história natural do homem como espécie animal [...] Mas o momento em que o homem se separou do reino animal - e isto aconteceu quando o homem segurou pela primeira vez os instrumentos primitivos de pedra e de madeira - naquele momento começou a criação e acumulação de cultura, isto é, do conhecimento e da capacidade de todos os tipos para enfrentar e subjugar a natureza (Trotski, 1981, p.51).

Trotski contribui ainda mais com nosso estudo quando destaca entre o conjunto de elementos constitutivos da cultura, os que se impregnam na formação da consciência social. Segundo ele, essa é:

[...] a parte mais preciosa da cultura é aquela que se deposita na consciência do próprio homem: o método, os costumes, a capacidade, a habilidade que adquirimos e que se desenvolve partindo de toda a cultura material préexistente e que, embora se prendendo a ela, faz com que progrida de acordo com a época (Trotski, 1981, p.52).

Por esse motivo o autor trata esses elementos culturais relacionados à formação da consciência social como fundamentais no desenvolvimento da base material da existência.

[...] Deste modo, em sua própria origem a cultura é uma síntese da dupla capacidade de agir fisicamente e de representar mentalmente, que o homem adquire ao se ir constituindo fisiológica e psiquicamente em animal diferenciado. Sendo uma síntese, é uma reunião de modos opostos de ser, de produzir. Desvenda-se, assim, um aspecto capital do conceito de cultura: seu caráter de mediação de toda realização humana [...] (Vieira Pinto, 1979, p.135).

Entendido dessa forma, a cultura no campo marxista aparece desde as elaborações de Marx e Engels, por mais que ambos não usassem esse termo ou tenham escrito tratados específicos sobre o tema. Em seus trabalhos, essa discussão é recorrente, principalmente, aliada às discussões sobre a constituição do ser social, dentre os quais, destacamos Os Manuscritos de Paris e A Ideologia Alemã como principais referências.

Em A Ideologia Alemã Marx e Engels nos apresentam os principais conceitos, leis e categorias consideradas como fundamentais para construção de sua teoria, assumidos como imprescindíveis no presente estudo. Estes autores explicam a produção da vida e a construção histórica da cultura a partir das relações sociais baseadas na propriedade privada dos 
meios de produção e na exploração do homem pelo homem. Estas relações e suas condições levam à construção de uma dada ideologia, que é determinada por essas condições de existência. Conhecer todo esse sistema é visto como necessário para que entendamos o desenvolvimento da cultura.

Ainda nessa obra, são lançados os princípios básicos que orientam as elaborações no campo marxista, tais como: a indissociabilidade entre a teoria e a realidade, a determinação em última instância da base material sobre a consciência, o confronto necessário entre aparência e essência, uma ontologia do homem e por sua vez, da sociedade.

Partimos, então, dessas premissas orientadoras para compreensão da cultura no campo do materialismo histórico dialético, analisado-a como produto e ao mesmo tempo formadora do gênero humano e de maneira alguma desatrelada da base material da existência.

$\mathrm{Na}$ geração de intelectuais marxistas posteriores a Marx, é possível observar uma continuação dos estudos marxianos, assim como, tratados específicos sobre cultura ${ }^{5}$. Apresentaremos a seguir algumas dessas discussões, já que não é possível nesse trabalho dar conta de forma rigorosa e satisfatória de todo esse universo teórico. Em geral, e sempre relacionado ao momento histórico da produção, os autores irão - alguns mais outros menos - aprofundar as discussões específicas sobre cultura.

Perry Anderson (2004), em sua análise sobre o marxismo ocidental, apresenta um balanço da produção marxista e indica o rumo que tal produção seguiu. Devido às condições político-econômicas enfrentadas por essa geração, a produção marxista, em linhas gerais, tendeu a um afastamento do marxismo clássico, da produção de Marx e Engels, principalmente pela dissociação da produção teórica em relação à luta revolucionária. Na sua avaliação, Anderson aponta que em contrapartida a análise do capital, tema enfrentado pelo marxismo clássico, foi promovido à

\footnotetext{
${ }^{5}$ Podemos apontar alguns autores que de alguma forma se aproximam dessa discussão, de acordo com nossos estudos, com maior destaque, em ordem cronológica aproximada apresentamos: Plekanov, Lênin, Lukács, Gramsci, Trotsky; mais recentemente o grupo de historiadores ingleses, entre eles: Eric Hobsbawm, E.P. Thompson. Ressaltamos que não foi possível, nos limites deste trabalho, realizar uma revisão pormenorizada de toda a produção neste campo, tendo sido feita a escolha pelos marxistas mais próximos de nossa concepção neste momento.
} 
ascensão da discussão de novas temáticas no campo do marxismo tendo como destaque a cultura ${ }^{6}$. É nesse contexto que trataremos a produção a seguir, nesse primeiro momento apenas apresentado-as.

As elaborações contemporâneas se debruçaram sobre a questão cultural procurando estabelecer uma discussão própria do seu momento histórico, contextualizando-a com o desenvolvimento do capitalismo, a divisão da sociedade em classes, a produção e apropriação cultural de forma geral. A necessidade dessa discussão se deu por motivos diferentes, tanto por questões político-partidárias, como por questões meramente acadêmicas $^{7}$.

Em seu texto "Velha e nova cultura", Lukács irá enfatizar que a sociedade se desenvolve num processo único, onde todos seus aspectos estão agregados. Por isso, não se pode determinar certa fase do desenvolvimento num aspecto da vida social sem que seus efeitos repercutam sobre todos os outros. Dessa forma, pode-se falar da cultura (Kultur) em seu aparente isolamento em relação às outras manifestações sociais. Efetivamente, se nós compreendermos corretamente a cultura ${ }^{8}$, podemos compreender em suas raízes o desenvolvimento das relações econômicas de sua época (Lukács, 2007).

Reconhecemos que os nexos e determinações entre a cultura e a luta de classes são decisivos como possibilidades de compreender o processo de construção do conhecimento em sua perspectiva histórica, determinada pelas relações que os homens constroem no processo atual da produção de sua existência, e que é a partir destas relações que se torna possível compreender o desenvolvimento cultural em sua materialidade.

Para tanto, a cultura precisa ser entendida como produto do processo produtivo, e por isso, é decisiva a noção de sua dupla natureza, como bem

\footnotetext{
${ }^{6}$ Foi sobretudo a Arte que, no domínio da cultura, mobilizou os maiores talentos e energias intelectuais do marxismo ocidental (Anderson, 2004, p.96).

${ }^{7}$ Não será possível tratar dessas questões fundamentais para análise da discussão no campo marxista nesse trabalho, indicamos para próximos estudos.

${ }^{8}$ Para Lukács compreender corretamente a cultura só é possível sem desatrelá-la das relações de produção e reprodução da existência.
} 
de consumo e bem de produção ${ }^{9}$, esses dois aspectos coexistem sempre em toda sociedade, pois são inerentes ao fato da existência humana (Vieira Pinto, 1979). Por conta da ordem social do capital, a possibilidade da cultura fica limitada, pois as condições humanas e sociais de desenvolvimento pleno estão comprometidas no momento em que a cultura assume o caráter de mercadoria, perdendo o pressuposto do homem como fim em si (Lukács, 2007).

No campo das lutas sociais fica perceptível o quanto a cultura adquire lugar estratégico a serviço da ideologia do imperialismo, e como ao mesmo tempo, toda produção que se desenvolva em contraposição à ordem hegemônica é severamente perseguida com o objetivo de ser extirpada, conforme explicitação de Fidel Castro:

O imperialismo empenha-se em destruir símbolos, do exemplo, das idéias. Quis destruí-los em Granada, quer destruí-los em El Salvador, na Nicarágua, em Cuba. Mas os símbolos, os exemplos, as idéias não podem ser destruídos; e quando seus inimigos crêem havê-los destruído, o que fazem na realidade é multiplicá-los (Castro apud Ianni, 1985, p.124).

A intervenção imperialista nos países explorados necessita extrapolar a esfera da economia para garantir êxito, ainda que ela seja determinante, muitas dessas incursões surgem disfarçadas com o rótulo da sofisticação, do mais avançado, porém outras não requerem nenhum tipo de véu, deixando claro o objetivo da política cultural imperialista, como pode ser observado a seguir neste trecho retirado de uma publicação patrocinada pela The American Assembly.

Quem controlar a educação define seu passado e [...] também seu futuro. O amanhã está nas mãos e no cérebro dos que estão sendo educados hoje... Devemos, sem restrições, exportar idéias e imagens que fomentem a liberdade individual, a responsabilidade política e o respeito à propriedade privada. Deve ser iniciada uma campanha para capturar a elite intelectual

\footnotetext{
9 [...] é a sua dupla natureza de bem de consumo enquanto resultado, simultaneamente materializado em coisas e artefatos e subjetivado em idéias gerais, da ação produtiva eficaz do homem na natureza; e de bem de produção, no sentido em que a capacidade, crescentemente adquirida, de subjugação da realidade pelas idéias que representam, constitui a origem de nova capacidade humana, a de idealizar em prospecção os possíveis efeitos de atos a realizar, conceber novos instrumentos e novas técnicas de exploração do mundo, e de criar idéias que significam finalidades para as ações a empreender (Vieira Pinto, 1979, p.124).
} 
ibero-americana através do rádio, da televisão, de livros, de artigos e folhetos, de mais doações, bolsas de estudo e premiações. Consideração e reconhecimento são os que mais agradam aos intelectuais e um programa com essas características poderá atraí-los (Tabs apud Ianni, 1985, p.126).

No intuito de afirmar a atualidade das formulações de Marx, Osvaldo Coggiola aponta que "a mundialização da cultura, como processo objetivo e decorrente da natureza tendencialmente mundial do capitalismo desde o seu nascedouro, tinha sido, como é óbvio, previsto por Marx". E que hoje, diante da "industrialização da cultura" a contestação cultural tem que atingir também características "industriais", ou seja, ganhar grandes proporções ao contrário das vanguardas do século passado e do nosso (Coggiola, 2001, p.10 -12).

Como contraponto a "crescente tendência à alienação produtiva e cultural, e na exacerbação de todas as desigualdades sociais" (Coggiola, 2001, p. 11), é que analisaremos a cultura a partir da contribuição de um dos líderes da maior revolução socialista da história da humanidade, identificando a importância e a tarefa estratégica da cultura para o processo revolucionário.

\section{Revolução e Cultura - contribuição de Leon Trotski}

Esse tópico acrescenta ao nosso artigo a contribuição de um autor pouco utilizado como referência na produção acadêmica, mas com grande penetração nas organizações anticapitalistas e nas lutas sociais. Tal desconsideração é compreensível, uma vez que a objetividade revolucionária de seus escritos aparece em contraposição à produção hegemônica da academia. O autor do qual falamos é Lev Davidovitch Bronstein, mais conhecido como Leon Trotski (1879-1940).

A produção teórica de Trotski está intimamente ligada à sua trajetória de vida, marcada pela participação na maior experiência revolucionária socialista $^{10}$, a revolução social é o eixo central de seus escritos, dedicando

\footnotetext{
${ }^{10}$ Com participação ativa no levante revolucionário, Trotski ocupará funções estratégicas para a consolidação da revolução, entre elas: presidente do soviete de Petrogrado em 1905, em 1917 torna-se presidente do novo soviete de Petrogrado, e como chefe do Comitê Militar Revolucionário do soviete, planeja e executa a insurreição que daria origem à
} 
boa parte de sua vida a analisar o contexto da Revolução Russa, o período pré- revolucionário, a transição socialista e o movimento internacional comunista. Entre guerras mundiais, guerra civil, perseguição política, exílio, a produção de Trotski destaca-se no sentido de apresentar o contexto de sua época, como de apontar alternativas para as conquistas revolucionárias. Sempre ligada a uma intervenção prática, seus estudos irão servir de instrumento para a classe proletária em ascensão em sua época, o que segundo Perry Anderson (2004), o coloca entre a geração de marxistas que não desatrelaram a produção teórica da atuação política ${ }^{11}$, estreitando sua ligação com o marxismo clássico de Marx e Engels.

Para efeito de nosso estudo sobre a cultura e emancipação humana, recorreremos à análise de textos de Trotski referentes a esse tema específico: Questões do modo de vida (1923); Literatura e Revolução (1924); Cultura e Socialismo (1924). Nesses textos procuramos identificar os nexos da cultura com o projeto revolucionário socialista; sua relação com a herança cultural da humanidade, inclusive burguesa; sua dependência ao novo modo de produzir a existência a emergir; e a possibilidade de uma cultura para além das classes sociais, uma cultura verdadeiramente humana.

$\mathrm{Na}$ sua origem a cultura se contrapunha ao que era dado ao homem pela natureza, o que era conquistado pela força do homem, como: campo arado e cultivado, diferente das matas virgens. Esta antítese conserva ainda seu valor substancial, pois nesse processo de adaptação da natureza às suas necessidades, o homem produz a sua existência ao mesmo tempo em que se constitui enquanto ser social. É nesse processo que a cultura ganha importância, ainda que as conquistas humanas sejam hoje mediadas pela

revolução de Outubro; posteriormente em 1918 é nomeado comissário do povo para o Exército e a Marinha e organiza o Exército Vermelho.

${ }^{11}$ Seus escritos, salvo algumas exceções, estão marcados pela militância e almejam fins políticos imediatos, com o que muitas vezes se inserem em polêmicas obscuras, dão por suposto o contexto que origina as reflexões, e não chegam a fornecer uma sistematização como o próprio autor gostaria, em outras condições, de oferecer. No prefácio à edição francesa de um de seus textos teóricos considerados mais importantes, Trotski declara: “A composição deste livro, complexo e imperfeito em sua arquitetura é a própria imagem das circunstâncias em que nasceu [...] Não foi, porém, o autor quem escolheu e adotou essa forma de discussão. Ela lhe foi imposta por seus adversários e pelo curso da evolução política [...]" (Miranda, 1981, p.9). 
sociedade de classes, fruto também dessa mesma produção histórica, fazendo com que cada classe dominante crie sua cultura (Trotski, 2007- a).

Consideramos pois, como fundamento, que a cultura se desenvolveu graças à luta do homem contra a natureza ${ }^{12}$, pela sua existência, pela melhoria de suas condições de vida. Mas partindo desse mesmo princípio também se desenvolvem as classes. No processo de adaptação à natureza, em conflito com as forças hostis, a sociedade humana vem-se delineando como uma complexa organização de classes. A estrutura classista da sociedade determinou, na medida decisiva, o conteúdo e a forma da história humana, isto é, as relações materiais e seus reflexos ideológicos. Isto significa que a cultura histórica assumiu um caráter de classe [...] Aqui existe efetivamente uma profunda contradição. Tudo aquilo que foi conquistado, criado, construído pelo esforço do homem e que serve para aumentar seu poder, é cultura. Mas como não se trata do homem considerado individualmente, mas o homem considerado socialmente, como a cultura é um fenômeno sóciohistórico pela sua natureza, e como a sociedade histórica tem sido e continua a ser uma sociedade de classes, a cultura acabou se tornando o instrumento fundamental da opressão de classe ${ }^{13}$. Marx dizia: "As idéias dominantes numa época são essencialmente as idéias da classe dominante daquela época". Isto também vale para a cultura no seu conjunto (Trotski, 1981, p.52).

Partindo da compreensão da realidade com suas contradições e mediações, percebe-se que todas as esferas da vida serão influenciadas e regidas pelas mesmas, o que não é diferente com a produção cultural que, atrelada à produção econômica, apresentará a contradição como elemento central do seu desenvolvimento. "A cultura espiritual é contraditória como a cultura material [...] A cultura é um fenômeno social" (Trotski, 1981, p.55 e 60). A cultura é, ainda segundo o autor, um momento da maior importância na "opressão de classe", não obstante, contraditoriamente, também possua um papel importante na luta para a "emancipação socialista"14.

\footnotetext{
${ }^{12}$ A afirmação "luta do homem contra a natureza", é melhor compreendida no decorrer do texto como luta contra as barreiras naturais.

${ }^{13}$ Mesmo na sociedade de classes, a cultura nunca será o instrumento fundamental da opressão, já que a mesma não se configura como uma condição da existência de primeira ordem.

14 Nas palavras do próprio autor, encontramos o seguinte: "Sim, a cultura é o instrumento principal da opressão de classe. Mas também a cultura, e apenas ela, pode tornar-se um instrumento da emancipação socialista". Fizemos a opção por parafrasear essa passagem, tomando a positividade da visão contraditória sobre a cultura, que nos permite analisa-la de forma dialética, ao tempo que retiramos a idéia da cultura como um "instrumento", o que nos traria alguns problemas para a análise desse fenômeno.
} 
Destacaremos para uma análise mais rigorosa, a obra Literatura e Revolução, escrita entre 1923 e 1924, por ser o maior e mais denso texto sobre a questão da cultura em sua íntima relação com a causa revolucionária. Trotski nesta obra realiza um balanço das produções literárias do período pré-revolucionário e pós-revolução, analisando a possível aproximação dos objetivos revolucionários, e sua contribuição para o desenvolvimento de uma cultura verdadeiramente humana.

Buscando analisar criticamente as obras de sua época, Trotski utiliza como principal critério as relações destas com o modo da existência ${ }^{15}$, estabelecendo os nexos necessários, o que garante uma prioridade ontológica para sua compreensão, "a cultura alimenta-se na seiva da economia. É preciso, porém, mais que o estritamente necessário à vida para que a cultura se desenvolva e aprimore”. O autor ressalta que não se deve utilizar dos métodos da economia para analisar a arte, pois a mesma possui seus próprios métodos.

É indiscutível que a necessidade da arte não é criada pelas condições econômicas. Mas tampouco a necessidade de alimentação é criada pela economia. A necessidade de alimentação e calor, é que cria a economia. Nem sempre se podem seguir somente os princípios marxistas para julgar, rejeitar ou aceitar uma obra de arte. Esta deve ser julgada, em primeiro lugar, segundo suas próprias leis, isto é, segundo as leis da arte. Mas só o marxismo pode explicar por que e como, num determinado período histórico, aparece tal tendência artística; em outras palavras, quem expressou a necessidade de certa forma artística, e não de outras, e porquê (Trotski, 2007-a, p.139-140).

Reforçando o princípio de que a partir do velho é que poderá surgir o novo, Trotski emprega grande esforço na defesa da apropriação dos bens culturais produzidos pela humanidade até então, inclusive da arte burguesa. A exemplo apresenta o desenvolvimento da cultura burguesa, que "começou vários séculos antes que a burguesia, por meio de uma série de revoluções, tomasse o poder do Estado. Quando apenas representava o Terceiro Estado, quase sem direitos, a burguesia já desempenhava um grande papel, que crescia sem cessar em todos os domínios do desenvolvimento cultural"

15 ...Ela (a arte) não representa um elemento desencarnado, alimentando-se de si mesmo, mas uma função do homem social, indissoluvelmente ligado a seu meio e a seu modo de vida (Trotski, 2007-a, p. 144). 
(Trotski, 2007-a, p.151). Assim, confirma o pressuposto da continuidade histórica alterada pelas ações do homem, expressa também na esfera da cultura,

[...] Uma nova classe não recomeça a criar toda a cultura desde o início, mas se apossa do passado, escolhe-o, retoca-o, o recompõe e continua a construir daí. Sem o uso do guarda-roupa de "segunda mão" do passado não haveria progresso no processo histórico (Ibidem, p. 143) [...] "Os dias que vivemos ainda não representam a época de uma nova cultura, mas no máximo seu limiar. Devemos em primeiro lugar nos apossar oficialmente dos elementos mais importantes da velha cultura, a fim de podermos ao menos abrir caminho à construção de uma cultura nova (Trotski, 2007-a, p.154).

A compreensão do atual contexto da luta de classe é essencial para perceber como é necessária a revolução, e como a arte é utilizada pela classe dominante de uma época ${ }^{16}$, daí o porquê dessa necessidade histórica de alteração radical do modo de produção da existência. Trotski irá apresentar como exemplo que "ele [o proletariado russo] precisou derrubar a sociedade burguesa pela violência revolucionária precisamente porque essa sociedade lhe barrava o acesso à cultura” também (Trotski, 2007-a, p.156).

Essa utilização da violência foi necessária porque, historicamente, o acesso aos bens culturais foi negado aos trabalhadores constituindo-se numa afronta sem precedentes. Numa sociedade organizada sob as normas da propriedade privada e da cisão em classes sociais a produção e o acesso dos bens culturais seguem a mesma orientação.

Não é preciso demonstrar que a separação da arte dos outros aspectos da vida social resulta da estrutura de classe da sociedade. Sua auto-suficiência, como se ela se bastasse a si mesma, constitui o reverso da medalha: a transformação da arte em propriedade das classes privilegiadas. A evolução da arte, no fundo, seguirá o caminho de uma crescente fusão com a vida, isto é, com a produção, as festividades populares e a vida coletiva (Trotski, 2007a, p.114).

\footnotetext{
${ }^{16}$ Onde está escrito que é impossível servir à burguesia por meio da arte? Da mesma forma como os deslizamentos geológicos revelam as camadas terrestres, as perturbações sociais revelam o caráter de classe da arte. Uma importância mortal atingiu a arte que se colocou fora da Revolução de Outubro simplesmente porque as classes às quais se vinculava por todo o seu passado sucumbiram. Sem o sistema burguês da propriedade da terra e seus costumes, sem as sugestões sutis das castas e dos salões, essa arte não vê sentido algum na vida, definha, torna-se moribunda e reduz-se a nada (Trotski, 2007-a, p.67).
} 
No seu texto "Questões do modo de vida", Trotski descreve minuciosamente as dificuldades do período pós-revolução, e a importância da formação para além da política, destacando os problemas oriundos de um baixo nível do padrão cultural do povo russo que impedia a realização de muitas conquistas da revolução de outubro.

Lênin se preocupava muito também com a questão do padrão cultural do povo russo, fazia a mesma análise que Trotski no que se refere aos prejuízos da revolução para um povo com uma carência de elementos básicos de formação cultural. Lunatcharski comenta no seu texto Lênin e a Arte que:

Lênin insistia com toda força em que nos seria muito mais fácil lutar e construir se tivéssemos herdado depois da derrubada da monarquia e das classes dominantes uma cultura burguesa mais desenvolvida. Repetia reiteradas vezes que essa cultura burguesa facilitaria ao proletariado dos países do Ocidente a possibilidade de acelerar depois de sua vitória a realização real e plena do socialismo (Lunatcharski, 1968, p. 192).

Trotski ressalta, ainda, a diferença entre classe operária e classe burguesa enquanto classe revolucionária, pois, ao contrário da burguesia que no processo revolucionário apenas assumiu a posição de classe dominante sem alterar a ordem social, os proletários, para além disso, têm como objetivo final a supressão das classes sociais.

É fundamentalmente falso opor a cultura e a arte burguesa à cultura e à arte proletárias. Estas últimas jamais existirão, porque o regime proletário é temporâneo e transitório. A significação histórica e a grandeza moral da revolução proletária residem no fato de que ela planta os alicerces de uma cultura que não será de classe, mas pela primeira vez verdadeiramente humana (Trotski, 2007-a, p.37).

Trotski, especificamente na obra "Literatura e Revolução", oferece elementos de uma das maiores experiências da história da humanidade, a revolução russa, que nos serve de lição para os empreendimentos de uma revolução socialista, de uma preparação em outro patamar, sem incorrer nos erros anteriores. Oferece subsídios teóricos fundamentais para pensarmos as estratégias para a formação dos militantes de hoje, e como os elementos da cultura podem contribuir nessa tarefa. 


\section{Considerações finais}

Mesmo sem aprofundarmos na origem e no real significado do conceito de cultura, essa análise no campo do marxismo já nos possibilita elencar diretrizes, orientações que demarcam a compreensão da cultura no campo da revolução social, ainda que apresentem definições diferentes, porém não excludentes apresentando questões como: a indissociabilidade da produção base material; o caráter de classe que ela assume na sociedade; a ontologia do ser social como chave para a compreensão da Teoria da Cultura; a utilização como ferramenta essencial para o processo revolucionário, e sua importância na constituição do homem enquanto ser genérico.

Consideramos fundamental compreender a cultura como um infinito complexo de conhecimentos científicos, de criações artísticas, de operações técnicas, de fabricação de objetos, máquinas, artefatos e tantos outros produtos da inteligência humana. E, não insistir na posição hegemônica, que não unifica todo esse mundo de entidades, tratando como subjetivas umas e objetivas outras, de modo a dar uma explicação coerente com um ponto de vista esclarecedor de toda essa extrema e diversificada multiplicidade da realidade concreta (Vieira Pinto, 1979). Ao mesmo tempo, tomaremos sempre cuidado quando analisarmos a compreensão da cultura num sentido ampliado, para não cometermos o equívoco de tratar como idênticos os diferentes complexos do ser social, como no caso entre trabalho e cultura.

[...] Os complexos ideológicos se distinguem do trabalho, não apenas pelo seu caráter fundado, mas também porque não cumprem a função social de produzir os meios de produção e de subsistência a partir da transformação da natureza, função específica do trabalho [...] (Lessa, 2007, p.110).

No esforço de unir os elos entre a produção material e espiritual fugindo da dicotomização, às vezes acabamos por tratar ambas como se fossem a mesma coisa, dessa forma desconsiderando as determinações históricas e muitas vezes atribuindo autonomia absoluta a cada esfera. Dentro do conjunto de complexos que compõe a concreticidade, se faz 
presente a interdependência entre as esferas da produção da vida que têm como última instância a produção econômica.

Para realizar essa análise precisamos recorrer constantemente à lógica dialética, que possibilita compreender as relações entre as diferentes esferas da produção sem perder de vista as especificidades de cada uma, garantindo-nos uma apreensão do real em seu movimento. A dialética marxista é muito mais que uma técnica a ser empregada, ela é o próprio movimento da realidade, por isso, "não pode ser imposta aos fatos, deve ser deduzidas dos fatos, da sua natureza, do seu desenvolvimento" (Trotski, 1981, p. 57).

Quando afirmamos que há uma interdependência dialética entre as esferas da produção da vida, não fazemos apenas porque precisamos defender uma perspectiva teórica, mas sim pelo compromisso de apreender a realidade concreta na máxima profundidade possível. Por isso, “a crítica marxista na ciência deve ser não apenas vigilante, mas também prudente: do outro modo pode degenerar [...]" (Trotski, 1981, p. 57).

Sobre essa relação de reciprocidade e de determinação histórica, Engels em sua carta a B. Borgius de 1894, enfatizará que o desenvolvimento histórico em última instância é determinado pelas condições econômicas, ressaltando que dois pontos devem ser precisados, entre eles:

[...] o desenvolvimento político, jurídico, filosófico, religioso, literário, artístico, etc., repousam sobre o desenvolvimento econômico. Mas todos eles atuam, igualmente, uns sobre os outros, bem como sobre a base econômica. E isto porque a situação econômica não é a causa, o único motor, e todo o resto simples ação passiva. Ao contrário, sempre existe ação recíproca sobre a base da necessidade econômica, que sempre predomina em última instância [...] (Engels, 1981, p. 231).

Compreender a base econômica como última instância não significa afirmar uma determinação unidirecional, como é empregado pelo estruturalismo, mas sim identificar onde se expressa o centro de toda existência social, o pólo que precisa ser transformado para assegurar os avanços conquistados nas outras esferas da vida, por isso seria uma equívoco pensarmos de outra forma, pois estaríamos negando a capacidade humana de intervenção na produção de sua sobrevivência. 
Criticando os leitores apressados de Marx, Teixeira chama a atenção que a compreensão da determinação material marxiana está vinculada à interatividade social, "a determinação das forças produtivas sobre a forma social não é unidirecional, imediata, nem imutável [...]. Pelo contrário, a relação entre os principais complexos da existência social se faz de forma interativa, conformando reciprocidade de determinações, e é objeto de constante transformação no decurso do tempo" (Teixeira, 1999, p. 218).

Após essa breve exposição a respeito dos pressupostos dialéticos dos quais partimos, podemos caminhar na compreensão de como "se desenvolve a consciência". Nesse processo é impossível desconsiderar "a produção da cultura, no movimento real de determinação e reciprocidade", Marx e Engels irão destacar que é necessário,

[...] em cada caso particular, a observação empírica (que se atem aos dados reais) mostre nos factos, e sem qualquer especulação ou mistificação, o elo existente entre a estrutura social e política e a produção [...] A produção de idéias, de representações e da consciência está em primeiro lugar directa e intimamente ligada a actividade material e ao comércio material dos homens [...] (Marx e Engels, 1980, p. 25-26).

Nos Manuscritos de 1844, Marx reforça a tese da determinação e interação entre as esferas da produção da vida, apresentando-a no processo de superação da alienação.

[...] Religião, família, Estado, direito, moral, ciência, arte, etc., são apenas modos particulares da produção e caem sob a sua lei geral. A superação positiva da propriedade privada, enquanto apropriação da vida humana, é por conseguinte a superação positiva de toda a alienação, portanto o retorno do homem desde religião, família, Estado, etc., à sua existência humana, isto é social. A alienação religiosa como tal só se desenrola no terreno da consciência //, // do interior do homem, mas a alienação econômica é a da vida efetivamente real - a sua superação abrange por conseguinte ambos os lados (Marx, 1989, p.170).

Realizamos essa necessária digressão para apresentar como a produção marxiana e marxista nos auxilia na compreensão da realidade, e nesse caso especificamente na discussão sobre a cultura. Feito isso, passamos a analisar a produção sobre cultura sob um patamar materialista que preserva a historicidade do fenômeno social e apreende o movimento dialético na realidade concreta. 
Entender como o trato com a cultura possibilita a manutenção ou a superação do modo de produção capitalista, qual a sua contribuição para a manutenção do status quo vigente, e como a mesma pode ser utilizada como arma para a classe trabalhadora na sua luta contra o capital, é um desafio. O desenvolvimento cultural precisa auxiliar no processo de emancipação humana, para isso é urgente combater as teorias que irão dissociar a cultura das relações de produção, pois essas, ao contrário do que dizem, possuem um posicionamento político definido, qual seja, manter a ordem social do capital com a classe trabalhadora sob o julgo dessa relação social.

Essa análise da cultura no campo do marxismo já nos possibilita elencar diretrizes, orientações que demarcam a compreensão da cultura no campo da revolução social, como: a indissociabilidade da sua base material, a produção econômica; o caráter de classe que ela assume nesta sociedade; a ontologia do ser social como chave para a compreensão da cultura; a utilização da cultura como ferramenta para o processo revolucionário, e sua importância na constituição do homem enquanto ser genérico.

É preciso que a classe trabalhadora, por dentro dos seus organismos, repense a importância de outra possibilidade de trato com o conhecimento da cultura, que não pode ser qualquer uma muito menos a predominante na sociedade capitalista, entre elas as pós-modernas, essa tem de apresentar outros princípios que auxiliem no processo de emancipação humana.

\section{Referências}

ANDERSON, Perry. Considerações sobre o marxismo ocidental: nas trilhas do materialismo histórico. São Paulo: Boitempo, 2004.

BOSI, Alfredo. Dialética da colonização. São Paulo: Companhia das Letras, 1992.

CARDOSO, Ciro Flamarion. O conceito de cultura: um pomo de discórdia. Mimeo, 2007.

COGGIOLA, Osvaldo. "Globalização", economia e cultura. In: Universidade e ciência na crise global. São Paulo: Xamã, 2001.

ENGELS, Friedrich. Carta a B. Borgius. In: FERNANDES, Florestan. Marx $e$ Engels: História. São Paulo: Ática, 1981. 
FREITAS, Marcos Cezar de. O Conceito de tecnologia: o quarto quadrante do círculo de Álvaro Vieira Pinto. In: VIEIRA PINTO, Álvaro. O conceito de tecnologia. Rio de Janeiro: Contraponto, 2005.

IANNI, Octávio. Imperialismo e cultura. In: CHASIN, J. Revista Ensaio 14. São Paulo: Ensaio, 119-128, 1985.

LENIN, Vladimir Ílitch Uliánov. Cultura e revolução cultural. Rio de Janeiro: Civilização Brasileira, 1968.

LÉONTIEV, Aléxis. O homem e a cultura. IN: ADAM, Y, et.al. Desporto e desenvolvimento Humano. Lisboa: Seara Nova, 1977.

LESSA, Sérgio. Trabalho e proletariado no capitalismo contemporâneo. São Paulo: Cortez, 2007.

LUKÁCS, George. Introdução a uma Estética Marxista: Sobre a Categoria da Particularidade. Rio de Janeiro: Civilização Brasileira, 1968.

LUKÁCS, György. Ontologia do ser social: os princípios ontológicos fundamentais de Marx. São Paulo: Livraria Editora Ciências Humanas, 1979.

LUKÁCS, György. Velha e Nova Cultura. Disponível em: http://www.marxists.org/portugues/lukacs/1920/misc/velhaenovacultura.ht m. Acessado em: 08/10/2007.

LUNATCHARSKI, Anatóli. Lênin e a arte. In: LENIN, Vladimir Ílitch Uliánov. Cultura e Revolução Cultural. Rio de Janeiro: Civilização Brasileira, 1968, p.183-197.

MARX, Karl e ENGELS, Friedrich. A ideologia Alemã. Vol. I. 4ª ed. Portugal: Editorial Presença; Brasil: Martins Fontes, 1980.

MARX, Karl. Trabalho alienado e superação positiva da auto-alienação humana. In: FERNANDES, Florestan (Org). Marx e Engels: História. São Paulo: Ática, 1989.

MÈSZÀROS, István. A teoria da alienação em Marx. São Paulo: Boitempo, 2006. MIRANDA, Orlando (Org). Leon Trotski: política. São Paulo: Ática, 1981.

MORAES, Maria Célia Marcondes de. Recuo da teoria. In: MORAES, Maria Célia Marcondes de (Org.). Iluminismo às avessas: produção de conhecimento e políticas de formação docente. Rio de Janeiro: DP\&A, 2003, p.151-167.

SODRÉ, Muniz. A verdade sedurida: por um conceito de cultura no Brasil. Rio de Janeiro: CODECRI, 1983. 
TEIXEIRA, Paulo Tomaz Fleury. A individualidade humana na obra Marxiana de 1843 a 1848. In: Ensaios Ad Hominem. n. 1, Tomo I - Marxismo, São Paulo: Estudos e Edições Ad Hominem, 1999, p. 175 - 246.

TROTSKY, Leon. Literatura e Revolução. Rio de Janeiro: Jorge Zahar Ed., 2007a.

TROTSKI, Leon. A revolução permanente. São Paulo: Expressão Popular, 2007b.

TROTSKI, Leon. Cultura e socialismo. In: MIRANDA, Orlando (Org). Leon Trotski: política. São Paulo: Ática, 1981.

TROTSKY, Leon. Questões do modo vida. Publicações LBI, s/d.

VIEIRA PINTO, Álvaro. Teoria da Cultura. In: Ciência e existência: problemas filosóficos da pesquisa científica. $2^{\mathrm{a}}$ ed.. Rio de Janeiro: Paz e Terra, 1979. Cap. VI. p. 119-138. 